Article

\title{
Acute Toxicity and Gastroprotective Effect of the Schiff Base Ligand $1 H$-Indole-3-ethylene-5-nitrosalicylaldimine and Its Nickel (II) Complex on Ethanol Induced Gastric Lesions in Rats
}

\author{
Mohamed Mustafa Ibrahim ${ }^{1, *}$, Hapipah Mohd Ali ${ }^{2}$, Mahmood Ameen Abdullah ${ }^{3}$ and \\ Pouya Hassandarvish ${ }^{3}$
}

1 Department of Chemistry, University of Hail, Hail 81451, Saudi Arabia

2 Department of Chemistry, University of Malaya, Kuala Lumpur 50603, Malaysia; E-Mail: hapipah@um.edu.my

3 Department of Molecular Medicine, University of Malaya, Kuala Lumpur 50603, Malaysia; E-Mails: mahmood955@yahoo.com (M.A.); pouya3132@gmail.com (P.H.)

* Author to whom correspondence should be addressed; E-Mail: mohd_hashm4@hotmail.com; Tel.: +966-5092-03196.

Received: 12 September 2012; in revised form: 4 October 2012 / Accepted: 5 October 2012 / Published: 22 October 2012

\begin{abstract}
The present study was performed to evaluate the gastroprotective activity of Schiff base ligand derived from the condensation reaction of tryptamine (an indole derivative) and 5-nitrosalicylaldehyde (TNS) and its nickel (II) complex against ethanol-induced gastric ulcer in rats. The compounds were orally administered with low $(30 \mathrm{mg} / \mathrm{kg})$ and high $(60 \mathrm{mg} / \mathrm{kg})$ doses to ulcer-induced Sprague-Dawley rats. Macroscopically, the ulcer control group exhibited severe mucosal injury, whereas pre-treatment with either cimetidine or TNS and its nickel (II) complex each resulted in significant protection against gastric mucosal injury. Flattening of gastric mucosal folds was also observed in rats pretreated with TNS and its nickel complex. Histological studies of the gastric wall of ulcer control group revealed severe damage of gastric mucosa, along with edema and leucocytes infiltration of the submucosal layer compared to rats pre-treated with either cimetidine or TNS and its nickel (II) compound, where there was marked gastric protection along with reduction of edema and leucocytes infiltration of the submucosal layer. Acute toxicity study done on mice with a higher dose of $5 \mathrm{~g} / \mathrm{kg}$ of TNS and its nickel (II) complex did not manifest any toxicological signs. Research finding suggest that TNS and its nickel (II) complex could be considered as effective gastroprotective compounds.
\end{abstract}


Keywords: Schiff bases; metal complexes; tryptamine; anti-ulcer; cimetidine; histology

\section{Abbreviations: \\ $\mathrm{ICR}=$ Institute of cancer research \\ S.E.M = Standard error mean}

\section{Introduction}

Schiff bases which are a class of compounds containing an azomethine group $(-\mathrm{C}=\mathrm{N}-)$, have drawn attention for a long time due to their biological activities [1]. Indole and its derivatives are secondary metabolites that are present in most plants such as unripe bananas, broccoli, clove, almost all flower oils (e.g., jasmine and orange blossoms) and coal tar [2,3]. In the pharmaceutical field it has been discovered that it acts as an antimicrobial and anti-inflammatory [4]. A great deal of information regarding the properties of synthetic Schiff bases of potential biological interest has come to light during the last few years, as several of these compounds were characterized and used as models for a series of systems [5-9]. Metal complexes have been used widely to treat cancer, arthritis and diabetes [10]. Copper (II) complexes are known to be effective against rheumatoid arthritis and they also show anti-ulcer activity [11,12]. This is significant because gastrointestinal irritation often precludes treatment by other antiarthritic drugs. This is in line with the role of copper in generally preventing gastrointestinal damage by acidic anti-inflammatory agents [12].

In a previous paper we reported the anti-ulcerogenic activity of the Schiff base derived from tryptamine and 5-chlorosalicyldehyde and its nickel and copper complexes [13]. Continuing with this field of study we highlight here the anti-ulcer activity of a nitro-substituted Schiff base analogue and its nickel (II) complex.

\section{Results and Discussion}

\subsection{Chemistry}

The reaction of tryptamine with 5-nitrosalicylaldehyde afforded the ligand $1 H$-indole-3-ethylene-5nitrosalicylaldimine (TNS) in a good yield. The reaction of this ligand with nickel (II) salts gives the corresponding nickel (II) complex with 1:2 metal-to-ligand ratio, as shown in Scheme 1 below.

\subsection{Results}

\subsubsection{Acute Toxicity Study}

No mortality occurred amongst the mice with dose levels of $2 \mathrm{~g} / \mathrm{kg}$ and $5 \mathrm{~g} / \mathrm{kg}$ of the Schiff base TNS and its nickel (II) complex during the study period. Behavioral observations did not show evidence indicative of significant drug toxicity. No abnormal macroscopic and microscopic changes of the organs were observed following macroscopic necropsy and histopathological examinations. The results suggested that the oral $\mathrm{LD}_{50}$ of these compounds was greater than $5 \mathrm{~g} / \mathrm{kg}$. 
Scheme 1. Reaction routes.

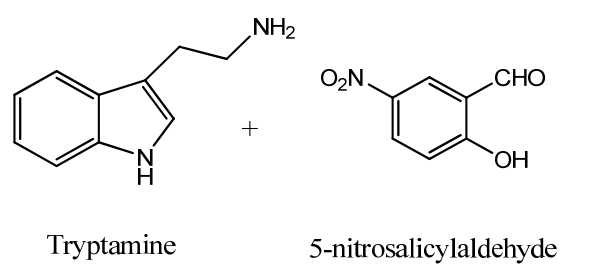

Tryptamine

$2 \mathrm{~h}$ reflux in ethanol<smiles>O=[N+]([O-])c1ccc(O)c(/C=N/CCc2c[nH]c3ccccc23)c1</smiles>

1H-Indole-3-ethylene-5-nitrosalicylaldimine (TNS)
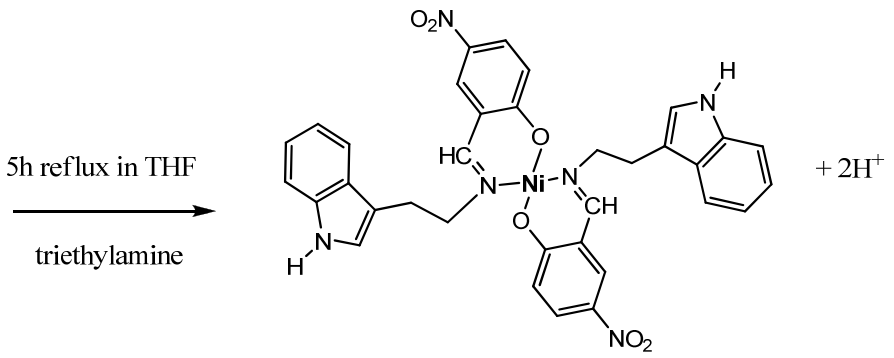

\subsubsection{Macroscopic Evaluation of Gastric Lesions}

Rats pre-treated with either $50 \mathrm{mg} / \mathrm{kg}$ cimetidine or the Schiff base TNS and its nickel (II) complex before being given absolute alcohol had significantly reduced areas of gastric ulcer formation compared to rats pre-treated with only 10\% Tween-20 [Table 1, Figure 1a-c]. Moreover, the compounds significantly suppressed the formation of the ulcers and it was interesting to note the flattening of gastric mucosal folds in rats pretreated with these compounds. It was also observed that protection of gastric mucosa was more prominent in rats pre-treated with both high and low doses of TNS ligand and high dose of the nickel (II) complex (Table 1). The significant inhibition of gastric ulcer in pretreatment with the compounds was compared with cimetidine which is a standard drug used for curing gastric ulcer.

Table 1. Effect of TNS and its nickel (II) complex on ulcer area, mucus weight, $\mathrm{pH}$ and inhibition percentage in rats.

\begin{tabular}{ccccc}
\hline Compound & $\begin{array}{c}\text { Total ulcer area }\left(\mathbf{m m}^{2}\right) \\
(\text { Mean } \pm \text { S.E.M) }\end{array}$ & Mucus weight (g) & pH & \% Inhibition \\
\hline $\begin{array}{c}\text { Tween-20 } \\
\text { (ulcer control) }\end{array}$ & $1438 \pm 58^{\mathrm{a}}$ & $0.58 \pm 0.05$ & $2.00 \pm 0.01$ & - \\
Cimetidine & $168 \pm 5^{\mathrm{b}}$ & $0.61 \pm 0.05$ & $3.00 \pm 0.01$ & 88 \\
$(+\mathrm{ve}$ control) & & & & \\
TNS (HD) & $3.6 \pm 0.2^{\mathrm{c}}$ & $1.33 \pm 0.05$ & $4.22 \pm 0.01$ & 100 \\
$\mathrm{TNS}(\mathrm{LD})$ & $3.6 \pm 0.2^{\mathrm{c}}$ & $1.60 \pm 0.05$ & $4.11 \pm 0.01$ & 100 \\
$(\mathrm{TNS})_{2} \mathrm{Ni}(\mathrm{HD})$ & $7.2 \pm 0.3^{\mathrm{d}}$ & $1.65 \pm 0.05$ & $3.68 \pm 0.01$ & 96 \\
$(\mathrm{TNS})_{2} \mathrm{Ni}(\mathrm{LD})$ & $26.4 \pm 0.2^{\mathrm{d}}$ & $2.00 \pm 0.05$ & $3.05 \pm 0.01$ & 95 \\
\hline
\end{tabular}

All values are expressed as mean \pm standard error mean. Means with different superscripts are significantly different. The mean difference is significant at the $p<0.05$ level. HD: High dose: $60 \mathrm{mg} / \mathrm{kg}$, LD: Low dose: $30 \mathrm{mg} / \mathrm{kg}$. 
Figure 1. (a) Macroscopic appearance of the gastric mucosa in a rat pre-treated with 10 $\mathrm{ml} / \mathrm{kg}$ of $10 \%$ Tween-20 (ulcer control). Severe hemorrhagic mucosal lesions are seen in the gastric mucosa. (b) Macroscopic appearance of the gastric mucosa in a rat pre-treated with Cimetidine $(50 \mathrm{mg} / \mathrm{kg})$. Injuries to the gastric mucosa are milder compared to the injuries seen in the ulcer control rat. (c) Macroscopic appearance of the gastric mucosa in a rat pre-treated with TNS $(60 \mathrm{mg} / \mathrm{kg})$. No injuries to the gastric mucosa are seen, and showed flattening of gastric mucosa.

(a)

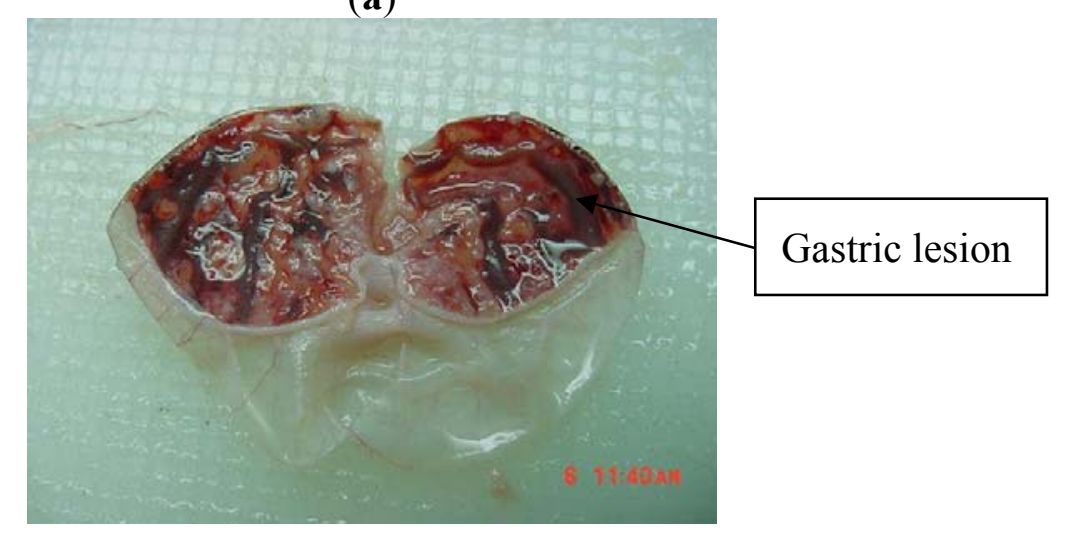

(b)

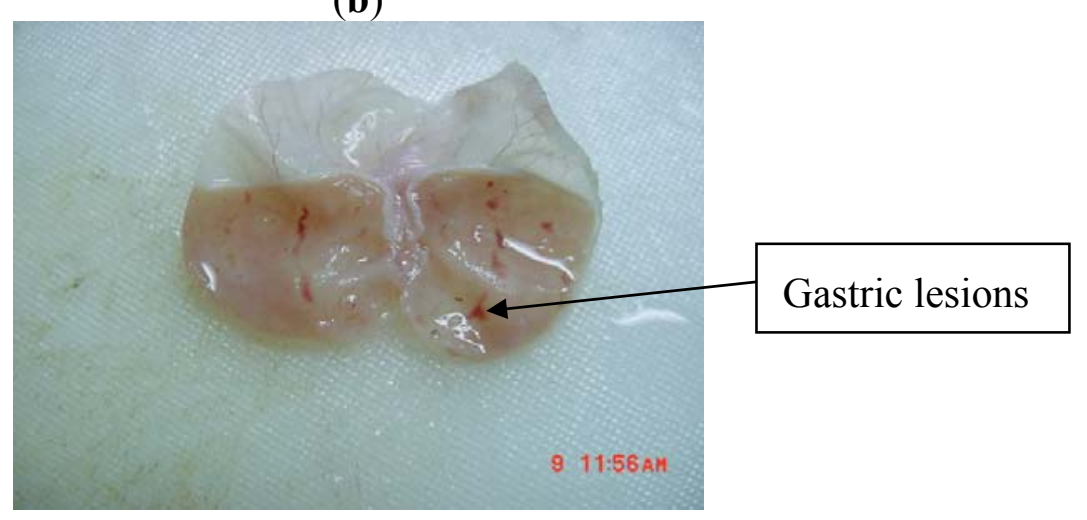

(c)

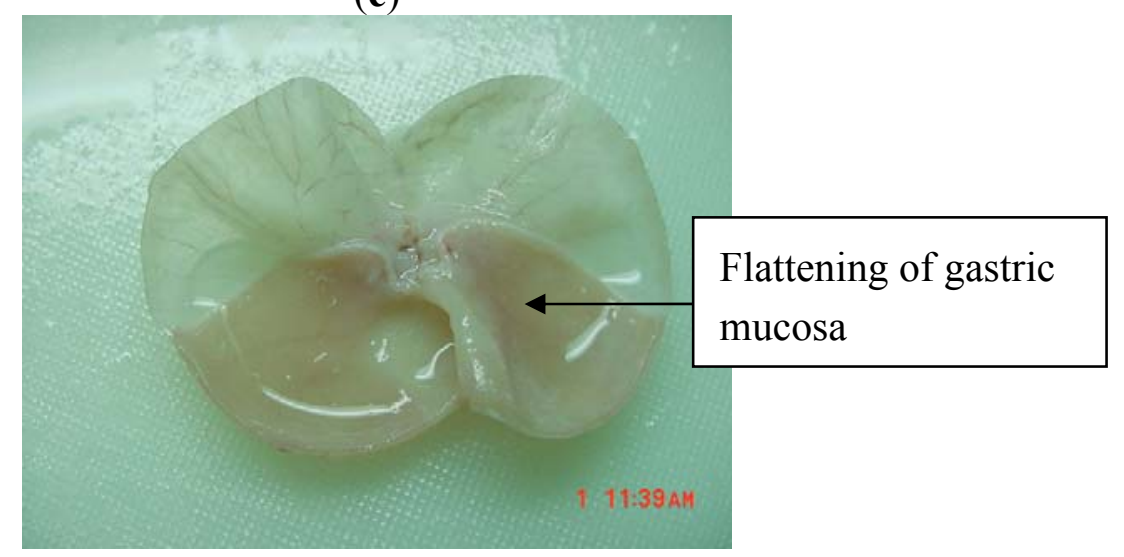

\subsubsection{Histological Examination}

Rats pre-treated with $10 \%$ Tween-20 prior to administration of absolute ethanol showed severe mucosal damage and the submucosa was markedly thickened by edema (Figure 2a). Deep hemorrhagic lesions in the mucosal layer and infiltration of leucocytes were observed in the submucosal layer. As 
seen in Figure 2c, rats pre-treated with TNS had milder mucosal damage, and less submucosal edema and leucocyte infiltration.

Figure 2. (a) Histological section of gastric mucosa in a rat pre-treated with $10 \mathrm{ml} / \mathrm{kg}$ of $10 \%$ Tween-20 (ulcer control) only. There is severe disruption to the surface epithelium, and edema of the submucosal layer with leucocyte infiltration. (b) Histological section of gastric mucosa in a rat pre-treated with $10 \mathrm{ml} / \mathrm{kg}$ of Cimetidine $(50 \mathrm{mg} / \mathrm{kg})$. There is mild disruption to the surface epithelium with mild edema and leucocytes infiltration of the submucosal layer. (c) Histological section of gastric mucosa in a rat pre-treated with $10 \mathrm{ml} / \mathrm{kg}$ of TNS $(60 \mathrm{mg} / \mathrm{kg})$. There is no disruption to the surface epithelium with no edema and no leucocytes infiltration of the submucosal layer.

(a)

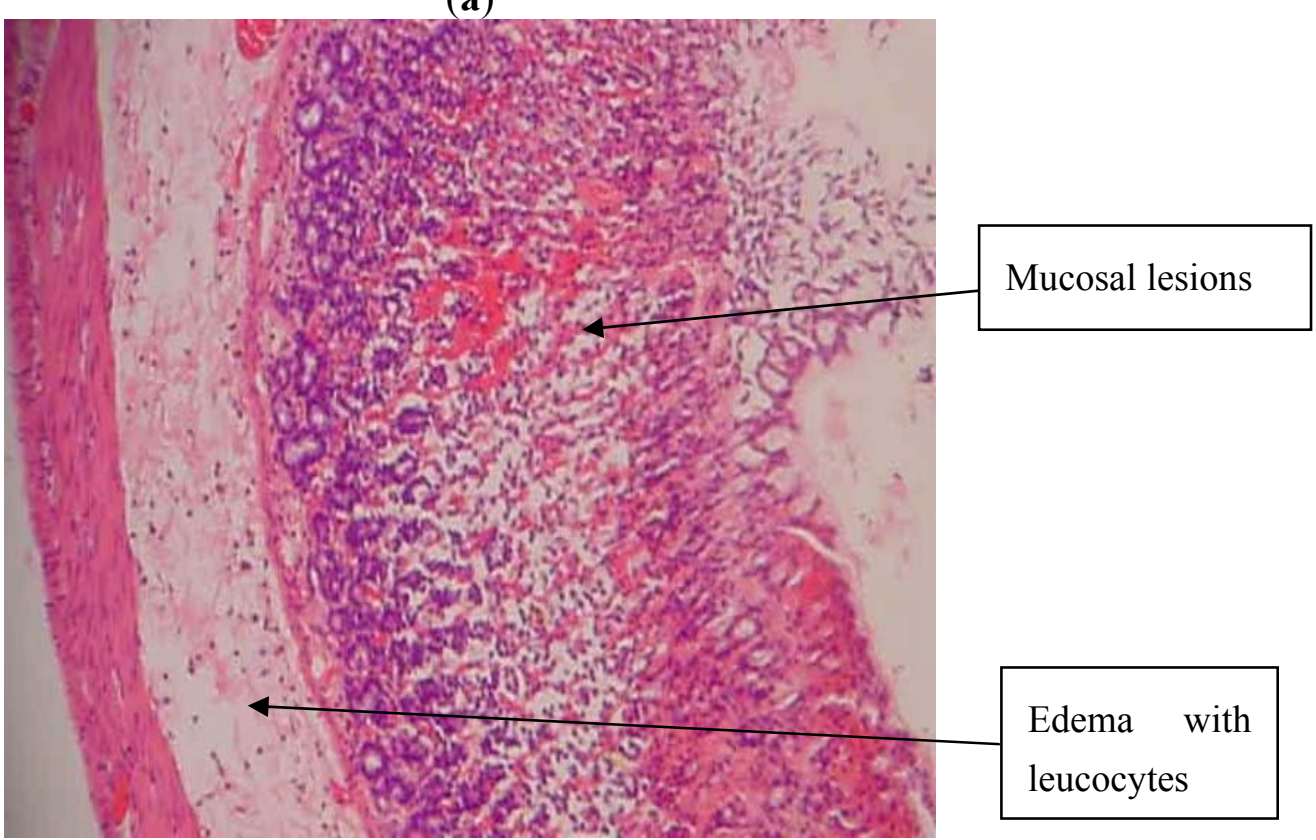

(b)

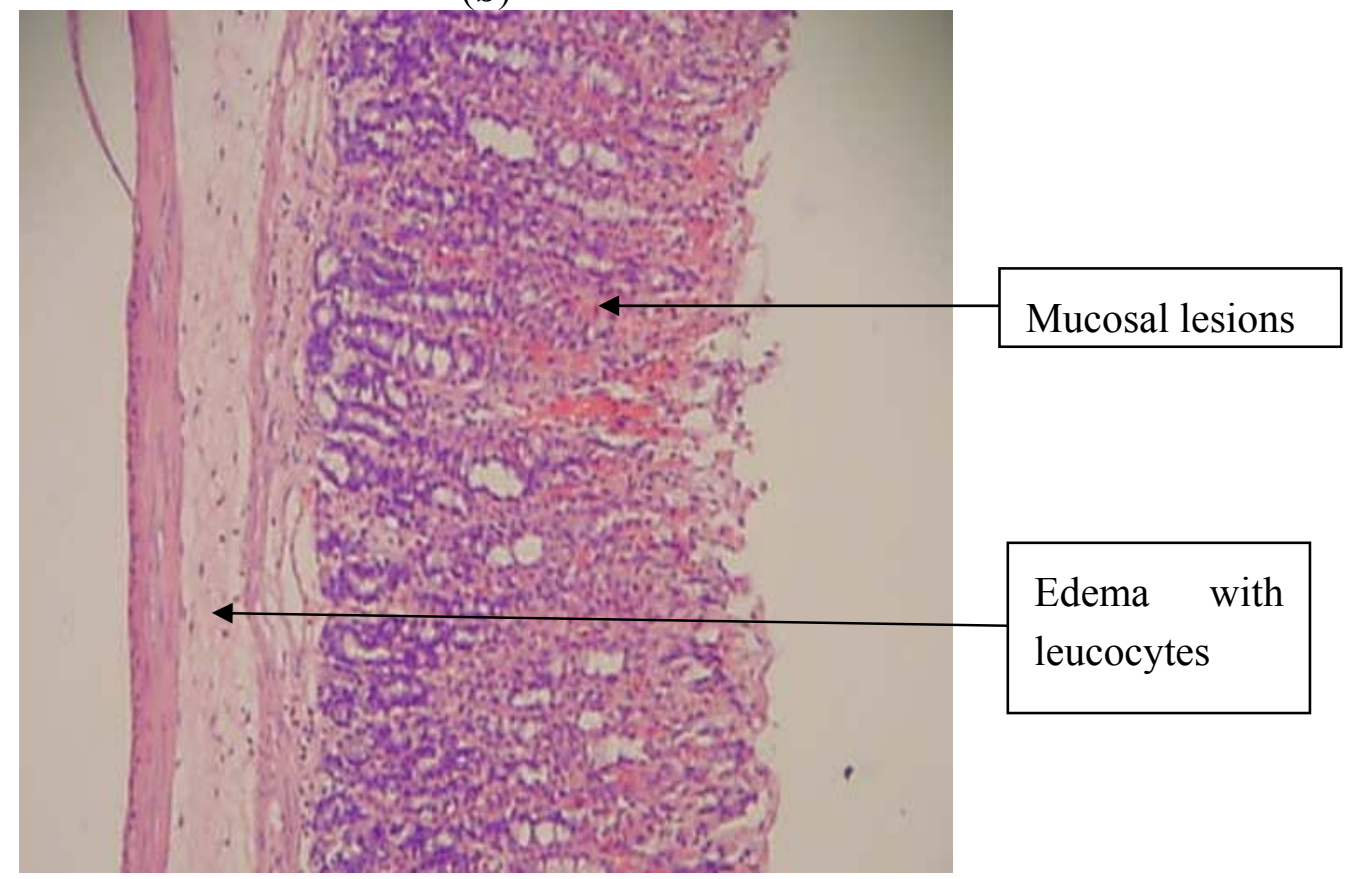


Figure 2. Cont.

(c)

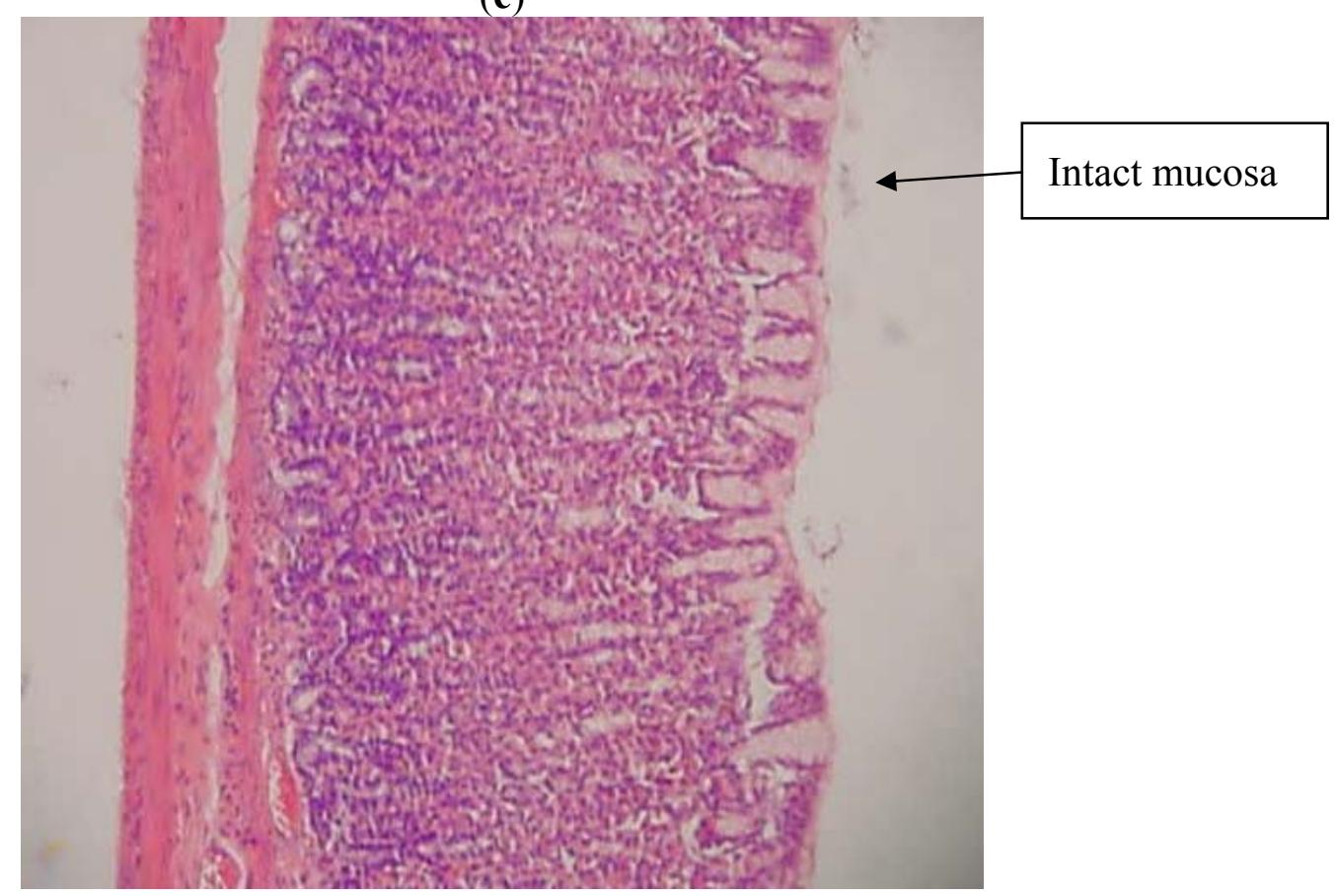

\subsection{Discussion}

The results of this study showed that TNS ligand is more effective as an anti-ulcer drug than its nickel (II) complex, yet, the ligand and its complex can be considered as potential anti-ulcer drugs compared to cimetidine as shown in Table 1.

This can be explained in the bases of reducing the acidity of the stomach juice as it can be implied from the $\mathrm{pH}$ values. These results also confirm the antisecretory ability of these compounds as reflected from the significant reduction of gastric juice acidity, beside the enhancement of mucus secretion. Ethanol is commonly used for inducing ulcers in experimental rats and leads to intense gastric mucosal damage. Ethanol shows its harmful effects either through direct generation of reactive metabolites, including free radical species that react with most of the cell components, changing their structures and functions, or promote enhanced oxidative damage [14,15]. It has been reported that the gastric cytoprotection might be mediated by at least two different mechanisms: one of them through prostaglandin synthesis, and the second one by increasing the production of mucosal glycoproteins $[16,17]$. Metal complexes were shown to enhance the formation of prostaglandine $E_{2}$ and are likely to participate in gastroprotective activity $[18,19]$. The results of the current study showed that rats pre-treated with TNS had significantly reduced gastric mucosal injury with less leucocyte infiltration of the submucosal layer. Cytoprotection was assessed by reduction in the macroscopically and microscopically visible lesions. Absolute alcohol would extensively damage the gastric mucosa leading to increased neutrophil infiltration into the gastric mucosa. Neutrophils are a major source of inflammatory mediators and can release potent reactive oxygen species such as superoxide, hydrogen peroxide and myeloperoxidase derived oxidants. These reactive oxygen species are highly cytotoxic and can induce tissue damage [20]. Furthermore, neutrophil accumulation in gastric mucosa has been shown to induce microcirculatory abnormalities [21]. Suppression of neutrophil infiltration during 
inflammation was found to enhance gastric ulcer healing [22]. Further studies are required to explore the detailed mechanism of action responsible for the anti-ulcer activity of these compounds.

\section{Experimental}

\subsection{Materials and Methods}

Cimetidine was used as the reference anti-ulcer drug, which belongs to a class of medication called histamine $\mathrm{H}_{2}$-receptors [23] and was obtained from the University Malaya Medical Centre (UMMC) Pharmacy. The drug was dissolved in 10\% Tween-20 and administered orally to the rats at a dosage of $50 \mathrm{mg} / \mathrm{kg}$ body weight $(5 \mathrm{~mL} / \mathrm{kg})$. Tryptamine and 5-nitrosalicylaldehyde were purchased from Sigma-Aldrich (Kuala Lumpur, Malaysia) and used without further purification.

\subsection{Preparation of the Ligand and Its Nickel Complex}

The ligand and its nickel (II) complex were prepared according to the method described in the literature [13]. Briefly: a solution of tryptamine $(0.30 \mathrm{~g}, 1.9 \mathrm{mmol})$ in acidified ethanol $(50 \mathrm{~mL}, \mathrm{pH} 4.5)$ was added to a boiling solution of 5-nitrosalisylaldehyde $(0.32 \mathrm{~g}, 1.9 \mathrm{mmol})$ in acidified ethanol $(50 \mathrm{~mL}, \mathrm{pH} 4.5)$. The mixture was refluxed for 2 hours. The solid product that had formed was filtered off, and recrystallized from THF (yield 54\%). It is soluble in acetone, THF and DMSO, but not soluble in either ethanol or water. Anal. Calc. for $\mathrm{C}_{17} \mathrm{H}_{15} \mathrm{~N}_{3} \mathrm{O}_{3}: \mathrm{C}, 66.01 ; \mathrm{H}, 4.89 ; \mathrm{N}$, $13.58 \%$. Found: $\mathrm{C}, 65.97 ; \mathrm{H}, 4.79 ; \mathrm{N}, 13.63 \%$. The complex was prepared as follows: to solution of nickel acetate tetrahydrate was added a solution of the Schiff base TNS in THF in 1:2 metal to ligand ratio. A few drops of triethylamine were then added. The mixture was refluxed for 5 hours. The product that had formed was filtered off, washed with THF and dried over anhydrous silica gel. Yield 76\%. The complex is insoluble in most organic solvents, but soluble in DMSO and DMF. Anal. Calc. for $\mathrm{C}_{34} \mathrm{H}_{28} \mathrm{~N}_{6} \mathrm{O}_{6} \mathrm{Ni}: \mathrm{C}, 60.41 ; \mathrm{H}, 4.14 ; \mathrm{N}, 12.43 \%$. Found: C, 60.32; H, 4.24; N, 12.21\%. After separation and purification, both TNS and its nickel (II) complex were suspended in 10\% Tween-20 solution. They were then orally administered to the rats at dosage of low dose $(30 \mathrm{mg} / \mathrm{kg})$ and high dose $(60 \mathrm{mg} / \mathrm{kg})$ body weight.

\subsection{Experimental Animals}

Adult male Sprague-Dawley rats were obtained from the Animal House, Faculty of Medicine, University of Malaya, Kuala Lumpur (Ethics No. PM 28/9/2007 MAA (R)). The rats weighed between 200-220 g. They were fasted for 24 hours before the experiment [24], but were allowed free access to drinking water till two hours before the experiment. During the fasting period, the rats were placed in six cages (groups), with wide-mesh wire bottoms to prevent coprophagia. Each cage contains six randomly selected rats.

Gastric ulcer was induced according to the method described by Robert et al. [25] with some modification in adult male Sprague-Dawley rats. Group 1 rats were ulcer control that received $10 \mathrm{~mL} / \mathrm{kg}$ of $10 \%$ Tween-20 orally by orogastric intubations, whereas Group 2 rats received oral doses of $50 \mathrm{mg} / \mathrm{kg}$ cimetidine $(10 \mathrm{~mL} / \mathrm{kg})$ as positive control. Group 3 and 4 rats received oral high dose $(60 \mathrm{mg} / \mathrm{kg})$ and low dose $(30 \mathrm{mg} / \mathrm{kg})$ of TNS respectively. Group 5 and 6 received oral high dose 
$(60 \mathrm{mg} / \mathrm{kg})$ and low dose $(30 \mathrm{mg} / \mathrm{kg}$ ) of the nickel (II) complex, respectively. One hour after this pre-treatment, rats were gavaged with absolute ethanol $(5 \mathrm{~mL} / \mathrm{kg})$ in order to induce gastric ulcers. The rats were euthanized 60 minutes later [26] by overdoses of diethyl ether and their stomachs were immediately excised. Each stomach was opened along the greater curvature, washed with distilled water and fixed in $10 \%$ buffered formalin for 15 minutes.

The stomachs were removed and the gastric juice was obtained from each stomach. The surface area $\left(\mathrm{mm}^{2}\right)$ covered by each lesion was measured [27], and the sum of erosion areas per rat stomach was estimated by using a microscope at magnification $\times 1.8$. Percentages of ulcerated surface (US) were calculated as: US $\left(\mathrm{mm}^{2}\right)=($ total area covered by ulcers/total corpus mucosal surface $) \times 100$. The ulcer index (UI) for each animal was then calculated as the mean ulcer score. Percentage inhibition (\%I) was determined as [(UI in control - UI in test group)/UI in control group] $\times 100$ [28].

After the stomach contents were collected, they were centrifuged and gastric juice was separated from the mucus. The mucus content was weighed and expressed in terms of grams [29] and the $\mathrm{pH}$ of the stomach juice was recorded.

\subsection{Acute Toxicity Test}

The acute toxicity was estimated according to the reported guidelines for testing of chemicals acute oral toxicity [30,31]. The test was used to determine a safe dose for the compounds TNS and its nickel (II) complex. Thirty six ICR mice (18 males and 18 females) were assigned equally into three groups ( 6 mice in each group) labeled as vehicle $10 \%$ Tween-20 $(5 \mathrm{~mL} / \mathrm{kg}) ; 2 \mathrm{~g} / \mathrm{kg}$ and $5 \mathrm{~g} / \mathrm{kg}$ for each of the compounds in 10\% Tween-20 preparation. These animals were subjected to overnight fasting (food but not water) prior to dosing. Food was withheld for a further 3 to 4 hours after dosing. The animals were observed for 30 minutes and 2, 4, 24 and $48 \mathrm{~h}$ after the administration for the onset of clinical or toxicological symptoms. Mortality, if any was observed over a period of 2 weeks.

\subsection{Histological Evaluation of Gastric Lesions}

Specimens of the gastric walls from each rat were fixed in $10 \%$ buffered formalin and processed in a paraffin tissue processing machine. Sections of the stomach were made at a thickness of $5 \mu \mathrm{m}$ and stained with hematoxylin and eosin for histological evaluation [23].

\subsection{Ethics}

Throughout the experiments, all animals received human care according to the criteria outlined in the "Guide for the Care and Use of laboratory Animals" prepared by the National Academy of Sciences and published by the U.S. National Institutes of Health.

\subsection{Statistical Analysis}

All values were reported as mean \pm S.E.M. The statistical significance of differences between groups was assessed using one-way ANOVA. A value of $p<0.05$ was considered significant. 


\section{Conclusions}

Novel Schiff base derived from tryptamine and 5-nitrosalicylaldehyde and its nickel (II) complex have been synthesized and studied for their gastroprotective activity. The compounds were significantly protecting the gastric mucosa against ethanol-induced injury in comparison to cimetidine. Such protection was ascertained by the reduction of gastric ulcer areas and by the production of mucus. Acute toxicity studies reveal that the compounds were found to be safe and no behavioral observations were detected for toxicity signs.

\section{Acknowledgments}

The authors express their keen thanks to University Malaya for its financial support through the grant No. PS145/2007B. Thanks were also to all those who contribute directly or indirectly in this research.

\section{References}

1. Barrajaa, P.; Sciabicaa, L.; Dianaa, P.; Lauriaa, A.; Montalbanoa, A.; Almericoa, A.M.; Dattoloa, G.; Cirrincionea, G.; Disaròb, S.; Bassob, G.; et al. Synthesis and photochemotherapeutic activity of thiopyrano[2,3-e]indol-2-ones, Bioorg. Med. Chem. Lett. 2005, 15, 2291-2294.

2. Waseem, G.; Mark, T.H. Indole alkaloid marine natural products: An established source of cancer drug leads with considerable promise for the control of parasitic, neurological and other diseases. Life Sci. 2005, 78, 442-453.

3. Lee, S.K.; Yi, K.Y.; Kim, S.K.; Suh, J.; Kim, N.J.; Yoo, S.; Lee, B.H.; Seo, H.W.; Kim, S.O.; Lim, H. Cardioselective anti-ischemic ATP-sensitive potassium channel (KATP) openers: Benzopyranyl indoline and indole analogues. Eur. J. Med. Chem. 2003, 38, 459-471.

4. Mohammad, T.; Moutaery, A.A. Menadione protects gastric mucosa against ethanol-induced ulcers. Exp. Tox. Path. 2005, 56, 119-129.

5. Tor, Y.; Libman, J.; Shanzer, A.; Lifson, S. Biomimetic ferric ion carriers: A chiral analog of enterobactin, J. Am Chem. Soc. 1987, 109, 6517-6518.

6. Grigg, R.; Armstrong, P. X $=\mathrm{Y}-\mathrm{ZH}$ systems as potential 1,3-dipoles. Part 25. Intramolecular cycloaddition reactions of pyridoxal imines of $\varepsilon$-alkenyl $\alpha$-amino esters. A possible new approach to pyridoxal enzyme inhibition. Tetrahedron 1989, 45, 7581-7586.

7. Hay, R.W. An introduction to Bioinorganic Chemistry; Williams, R.D., Ed.; Thomas: New York, NY, USA, 1976.

8. Dixon, N.E.; Gazzola, C. Jack Bean Urease (EC 3.5.1.5). Metalloenzyme. Simple biological role for nickel. J. Am. Chem. Soc. 1975, 97, 4131-4133.

9. Sigel, H.; Sigel, A. Nickel and its role in biology. In Metal Ions in Biological Systems; Dekker: New York, NY, USA, 1989; Volume 23, pp. 359-402.

10. Vančoa, J.; Marekb, J.; Trávníčekc, Z.; Račanskád, E.; Muselíke, J.; Švajlenováf, O. Synthesis, structural characterization, antiradical and antidiabetic activities of copper (II) and zinc (II) Schiff base complexes derived from salicylaldehyde and $\beta$-alanine. J. Inorg. Biochem. 2008, 102, 595-605.

11. Sorenson, J.R.J. Copper chelates as possible active forms of the antiarthritic agents. J. Med. Chem. 1976, 19, 135-148. 
12. May, P.M.; Williams, D.R. Role of low molecular weight copper complexes in the control of rheumatoid Arthritis. In Metal Ions in Biological Systems; Helmut Sigel: New York, NY, USA, 1981; Volume 12, pp. 283-317.

13. Mohamed, M.I.; Hapipah, M.A.; Mahmood, A.A.; Ward, T.R. Synthesis, structural characterization, and anti-ulcerogenic activity of Schiff bases derived from tryptamine, 5-chloro, 5-nitro, 3,5 ditertiarybutyl salicylaldehyde and their nickel (II), copper (II) and zinc (II) complexes. Polyhedron 2009, 28, 3993-3998.

14. Kato, S.; Kawase, T.; Alderman, J.; Inatomi, N.; Lieber, C.S. Role of xanthine oxidase in ethanol-induced lipid peroxidation in rats. Gastroenterology 1990, 98, 203-210.

15. Nordmann, R. Alcohol and antioxidant systems. Alcohol 1994, 29, 513-522.

16. Guardia, T.; Guzman, J.; Pestchanker, M.J.; Guerreiro, E.; Giordano, O.S. Mucus synthesis and sulfhydryl groups in cytoprotection mediated by dehydroleucodine, a sesquiterpene lactone. J. Nat. Prod. 1994, 57, 507-509.

17. Laura, S.; Favier, S.; Alejandra, M.M.; Graciela, H.W.; Eduardo, J.B.S.; Oscar, S.G. Lilian, P.; Carlos, E.T. Anti-ulcerogenic activity of xanthanolide sesquiterpenes from Xanthium cavanillesii in rats. J. Ethnopharm. 2005, 100, 260-267.

18. Franco, L.; Doria, D. Prostaglandins and nitric oxide in copper complex mediated protection against ethanol-induced gastric damage. Pharmaco. Res. 1997, 36, 395-399.

19. Alberghina, M.; La Spina, G.; Mangiameli, A.; Gulisano, M.; Sciotto, D.; Rizzarelli, E. Cytoprotective effect of copper (II) complexes against ethanol-induced damage to rat gastric mucosa. J. Inorg. Biochem. 1992, 45, 245-259.

20. Cheng, C.L.; Koo, M.W.L. Effect of Centella asiatica on ethanol induced gastric mucosal lesions in rats. Life Sci. 2000, 67, 2647-2653.

21. Bou-Abboud, C.F.; Wayland, H.; Panlsen, G.; Guth, P.H. Microcirculatory stasis precedes tissue necrosis in ethanol-induced gastric mucosal injury in rat. Dig. Dis. Sci. 1988, 33, 872-877.

22. Tsukimi, Y.; Nozue, C.; Okabe, S. Effects of teminoprazole, omeprazole and sucralfate on indomethacin-induced delayed healing of kissing gastric ulcers in rats. J. Gastroen. Hepatol. 1996, 11, 335-340.

23. Nina, H.; Robert, J.; Deirdre, M.; Hickey, B.; Lee, R.W. An International Historic Chemical Landmark: The discovery of Histamine $\mathrm{H}_{2}$-receptor Antagonists; SmithKline Beecham Pharmaceuticals: King of Prussia, PA, USA, 1998.

24. Garg, G.P.; Nigam, S.K.; Ogle, C.W. The gastric antiulcer effects of the leaves of the neem tree. Planta Med. 1993, 59, 215-217.

25. Robert, A.; Nezamis, J.E.; Lancaster, C.; Hanchar, A.J. Cytoprotection by prostaglandins in rats. Prevention of gastric necrosis produced by alcohol, $\mathrm{HCl}, \mathrm{NaOH}$, hypertonic $\mathrm{NaCl}$ and thermal injury. Gastroenterology 1979, 77, 433-443.

26. Paiva, L.A.F.; Rao, V.S.N.; Gramosa, N.V.; Silveira, F.R. Gastroprotective effect of Copaifera langsdorffii oleo-resin on experimental gastric ulcer models in rats. J. Ethnopharm. 1998, 62, 73-78.

27. Murakamu, S.; Kijima, H.; Isob, Y. Effects of salvianolic acid A on gastric $\mathrm{H}^{+}, \mathrm{K}^{+}$, -ATPase. Planta Med. 1990, 56, 360-363.

28. Njar, V.C.O.; Adesanwo, J.K.; Raji, Y. Methyl Angolensate: The antiulcer agent of stem bark of Etandrophragma angolense. Planta Med. 1995, 61, 91-92. 
29. Varley, H.; Gowenlock, A.H.; Bell, M. Practical Clinical Biochemistry; The Whitefrairs Press: London, UK, 1980; pp. 535-595.

30. OECD guideline for testing of chemicals. Available online: http://iccvam.niehs.nih.gov/ SuppDocs/FedDocs/OECD/OECD_GL425.pdf (accessed on 15 October 2012).

31. Dixon, W.J. Design and Analysis of Quantal Dose-Response Experiments (with Emphasis on Staircase Designs); Dixon Statistical Associates: Los Angeles, CA, USA, 1991.

Sample Availability: Samples of the compounds TNS and its nickel (II) complex are available from the authors.

(C) 2012 by the authors; licensee MDPI, Basel, Switzerland. This article is an open access article distributed under the terms and conditions of the Creative Commons Attribution license (http://creativecommons.org/licenses/by/3.0/). 